\title{
Arts engagement supports social connectedness in adulthood: findings from the HEartS Survey
}

Rosie Perkins ${ }^{1,2+}$, Adele Mason-Bertrand ${ }^{1,2+}$, Urszula Tymoszuk ${ }^{1,2}$, Neta Spiro ${ }^{1,2}$, Kate Gee ${ }^{1}$ and Aaron Williamon ${ }^{1,2^{*}}$

\begin{abstract}
Background: Loneliness is a public health challenge, associated with premature mortality and poorer health outcomes. Social connections can mitigate against loneliness, and there is evidence that the arts can support social connectedness. However, existing research on the arts and social connectedness is limited by focus on particular age groups and arts activities, as well as a reliance on typically small-scale studies.

Methods: This study reports survey data from 5892 adults in the United Kingdom, closely matched to the national profile in terms of sociodemographic and economic characteristics. It investigates the extent to which arts engagement is perceived to be linked with feelings of social connectedness, which forms of arts engagement are reported as most connecting, and how. Data were collected via the HEartS Survey, a newly designed tool to capture arts engagement in the United Kingdom and its associations with social and mental health outcomes. Demographic and quantitative data, pertaining to the extent to which arts engagement is perceived to be linked with social connectedness, were analysed descriptively. Qualitative data pertaining to respondents' perceptions of how arts engagement is linked with feelings of social connectedness were analysed using inductive thematic analysis.
\end{abstract}

Results: Results demonstrated that the majority of respondents (82\%) perceive their arts engagement to be linked with feelings of social connectedness at least some of the time. The forms of arts engagement most linked with feelings of social connectedness were attending a live music performance, watching a live theatre performance, and watching a film or drama at the cinema or other venue. Four overarching themes characterise how arts engagement is perceived to facilitate feelings of social connectedness: social opportunities, sharing, commonality and belonging, and collective understanding.

Conclusions: The findings suggest that arts engagement can support social connectedness among adults in the UK through multiple pathways, providing large-scale evidence of the important role that the arts can play in supporting social public health.

Keywords: Arts, Loneliness, Qualitative, Social connectedness, Social wellbeing, Survey

\footnotetext{
* Correspondence: Aaron.Williamon@rcm.ac.uk

${ }^{\dagger}$ Rosie Perkins and Adele Mason-Bertrand are joint first.

${ }^{1}$ Centre for Performance Science, Royal College of Music, London, UK

${ }^{2}$ Faculty of Medicine, Imperial College London, London, UK
}

(c) The Author(s). 2021 Open Access This article is licensed under a Creative Commons Attribution 4.0 International License, which permits use, sharing, adaptation, distribution and reproduction in any medium or format, as long as you give appropriate credit to the original author(s) and the source, provide a link to the Creative Commons licence, and indicate if changes were made. The images or other third party material in this article are included in the article's Creative Commons licence, unless indicated otherwise in a credit line to the material. If material is not included in the article's Creative Commons licence and your intended use is not permitted by statutory regulation or exceeds the permitted use, you will need to obtain permission directly from the copyright holder. To view a copy of this licence, visit http://creativecommons.org/licenses/by/4.0/. The Creative Commons Public Domain Dedication waiver (http://creativecommons.org/publicdomain/zero/1.0/) applies to the data made available in this article, unless otherwise stated in a credit line to the data. 


\section{Background}

Loneliness is an unpleasant emotional experience of dissatisfaction with the quality or quantity of one's social relationships [1]. Distinct from social isolation per se, loneliness can be emotional (the absence of close, emotional connections with others), social (the absence of social relationships or contact) [2], and existential (feeling disconnected from others and the universe) [3]. Loneliness is a public health problem, associated with a $26 \%$ increase in the risk of premature mortality $[4,5]$ as well as poorer cardiovascular and mental health outcomes [6]. Depression has been associated with increased risk of loneliness in young, middle-aged, and older adults, with those who report depression also reporting high levels of loneliness at around 38\% [7]. Other mental health disorders such as obsessivecompulsive disorder and phobia are also linked with loneliness [8]. As well as prolonged mental illness, loneliness is associated with ethnic minority status and living alone, with substance use problems [9], as well as sociodemographic and health-related factors within specific age groups, particularly younger adults (under 25 years) and older adults (over 65 years) [7, 10].

Given this context, attention has turned to ways to reduce loneliness. Recent syntheses of intervention studies for loneliness evidence a diverse range of intervention types, but with no effects seen in controlled studies $[1,11]$. Importantly, the reviews revealed that loneliness is not often a primary outcome measure but, rather, is typically reported along with other, related social measures. Indeed, loneliness is closely linked as a concept with (lack of) social connections, and these two terms are often used interchangeably in the literature. Conceptualised by Lee and Robbins, social connectedness refers to how one thinks of oneself in relation to other people, including how emotionally distant or connected one feels to individuals and society [12]. It can be defined as 'the opposite of loneliness, a subjective evaluation of the extent to which one has meaningful, close, and constructive relationships with others (i.e., individuals, groups, and society)', including caring about others, feeling cared for, and belonging to a group [13] . Moreover, social connectedness provides a useful counter concept to the deficit notion of loneliness [14], placing attention on what people can do in order to build social connections that are meaningful and fulfilling. Others explicitly position social connectedness as a potential means of reducing loneliness [15].

In this respect, the arts have emerged as an area of practice with potential for fostering social connectedness and reducing loneliness. Review articles, while pointing out limitations in the evidence base such as inconsistency in measurement tools and reporting of results [16], suggest that engagement in the arts can particularly support older adults. Dadswell and colleagues, for example, report a conceptual review indicating that participatory arts can strengthen and build relationships through social interaction, tackle inconsistences between expected and real relationships through enhancing self-worth and feelings of belonging, and allow older adults to contribute inclusively to their community [17]. Similarly, a review of forty-four studies indicated that participatory arts can promote reciprocal relationships among older adults, care givers, and the wider community [18]. Others concur that community-engaged art programmes are a 'promising tool' for addressing loneliness in older adults [19] and point to the connecting benefits of indoor gardening and visual art discussions [20].

Aside from review articles, which tend to focus on older adults, there is also a large body of work reporting that specific arts and cultural activities and interventions reduce feelings of loneliness and/or enhance social connections. Work with museums, for example, has shown that art and reminiscence workshops can support social inclusion and community building [21] and that tenweek museum programmes can help to reduce isolation and loneliness through creating opportunities for social inclusion, social engagement, and enhanced communication [22]. Furthermore, frequent engagement with museums, galleries, and exhibitions may be a protective factor against loneliness in older adults [23], and art therapy in art museums can promote social connectedness in older adults [24]. In music, a significant effect of music therapy on loneliness was shown among institutionalized older adults with mild depression compared with controls [25]. Drumming has been reported to enhance feelings of togetherness, belonging, and connectedness among soldiers experiencing PTSD [26] and mental health service users and their carers [27], while group singing has been shown to enhance emotional closeness between mothers and babies [28], and to mediate swift social bonding [29]. Sustained choral singing is also shown to enhance social connectedness [30] and reduce loneliness [31], and private music engagement has been shown to provide a sense of social connection and social surrogacy [32], or in other words people 'resort [ing] to temporary substitutes, so-called social surrogates, if direct social interaction is not possible' [33] . Finally, university students listen to music to reduce loneliness [34], a finding also seen in older adults [35].

In other art forms, older adults who read for pleasure were found to be significantly less lonely than adults who did not [36]. Indeed, arts activities including reading books were found to be successful predictors for social connectedness in older people [37]. In dance, line dancing in women aged over 60 years was found to increase social activity, including further community involvement and charitable work [38], and dancing in synchrony has been linked with enhanced social bonding 
[39]. Textile crafting has also been linked with social interaction and connectedness [40] as well as social connectedness through belonging [41]. In addition, community arts programmes, including crafts activities such as painting, pottery, and printmaking, were found to be particularly effective in mitigating loneliness among older adults and producing social inclusion [42]. Similarly, sandplay therapy was shown to reduce levels of loneliness and build social networks among migrant women [43]. Further to this, arts activities provided by social enterprises directly counteracted social isolation and loneliness in rural communities and enabled users to build social connections [44]. Finally, the arts can support community development through building group solidarity as well as individual and group identities [45] and can be used within community regeneration [46].

Although many studies have focused on older adults, there is also a body of research investigating how music can contribute towards positive social wellbeing in young adults. For example, musical engagement can help young people to strengthen relationships through the sharing of songs, and live music events can establish feelings of social connections between young adults and their friends and family [47]. Similarly, music can promote feelings of social connectedness, with young people viewing music as a means of connecting, sharing thoughts, opinions, and passions within others [48]. Music has also been identified as playing a key role in building shared identities amongst young adults. North and Hargreaves demonstrated how music can act as a 'badge' through which young people can judge others and convey aspects about themselves, with members of musical subcultures being found to hold positive perceptions of those with similar musical tastes [49]. Others have similarly highlighted how music acts as an important tool for the construction of group identities, with shared musical tastes creating a sense of belonging and community amongst young adults and music acting as a means of forging connections with others [50]. In addition, music making has been shown to support the social inclusion of young people within the criminal justice system, providing a space where participants could find respite from stigma and enjoy learning as part of a group [51].

While the majority of studies on young adults and the arts have focused on music, wider arts activities have also been shown to have positive social benefits for this group. Interviews and focus groups with young adults have demonstrated that attending recreational dance classes can establish as a sense of connection to cultural heritage and community, and develop social relationships [52]. Dance has been framed as an engaging social activity, with young women who danced regularly reporting higher rates of mindfulness and life satisfaction [53]. Furthermore, dancing was found to contribute towards the social wellbeing of young adults with autism, reducing tension and anxiety whilst building empathy, social skills, and ability to cope [54]. Participation in theatre groups has also been shown to promote social wellbeing, providing opportunities for selfexpression, problem solving, and life improvement amongst vulnerable young adults that developed collective efficacy [55].

These studies illuminate several gaps in current understanding of the relationships between the arts and social connectedness. First, review articles focus predominantly on older adults, meaning that synthesised or large-scale knowledge for other age groups is largely lacking. Second, a majority of the studies investigating the social wellbeing of young adults have focused on music activities or arts interventions undertaken with targeted groups. Within much of the existing literature, certain arts activities (including museum/gallery attendance and music) are prioritised, meaning that other forms of arts engagement - particularly those conducted at home, or in less structured ways - can be overlooked. Moreover, the majority of studies are relatively small-scale, and while there is consensus that arts engagement can support social connectedness - there is a lack of scrutiny of the psychosocial processes through which this happens. This article sets out to meet these gaps, answering three research questions:

RQ1: To what extent do adults perceive a link between their arts engagement and feelings of social connectedness?

RQ2: Which forms of arts engagement are most reported as linked with feelings of social connectedness?

RQ3: How is arts engagement perceived to facilitate feelings of social connectedness?

\section{Methods \\ Method}

Data were collected via the HEartS Survey (Health, Economic, and Social impacts of the ARTs), which was designed to capture current arts engagement in the United Kingdom (UK) and to explore its sociodemographic characteristics and correlations with mental and social wellbeing [56]. The HEartS Survey consists of seven sections: (1) demographics, (2) reported frequency and nature of arts and cultural activities, (3) open questions on arts engagement and social connectedness, (4) mental health and wellbeing, (5) physical activity, (6) social wellbeing, and (7) household income and arts spending [56]. This study draws on data from sections $1,3,4,6$, and 7 . 
Demographic information was collected in sections 1 and 7 regarding age, gender, geographic region, ethnicity, educational qualifications, living situation, and household income. Validated scales were used to collect information about social connectedness, loneliness, and depression in sections 4 and 6 . Social connectedness was measured using the 15-item Social Connectedness Scale [57], where a higher score (on a scale of 0-75) indicates more connectedness to others. Loneliness was measured using the Three-Item Loneliness Scale [58, 59], which identifies those scoring 6 or higher out of a possible 9 as lonely. Depression was measured using the eight-item Center for Epidemiologic Studies Depression Scale (CES-D). The number of selected depressive symptoms is summed, generating a score (0 to 8$)$. A score of three symptoms or more (out of the possible eight) has been commonly used for identifying cases of depression [60]. Where possible, we used standardised Office for National Statistics Census questions (including geographic regions, ethnicities, educational qualifications, and living situations) and attempted to match our sample to the national profile. Further information on the validated measures and the HEartS Survey is available elsewhere [56, 61].

Data to answer the research questions were drawn from three questions in section 3: Q1. Does your engagement with the arts and cultural activities you have told us about today [i.e., those identified by each respondent in section 2] help you to feel connected with other people? (measured on a 5-point scale: not at all, a little, around half the time, often, always); Q2. Of the arts and cultural activities you have told us about, which makes you feel most connected to other people? (Please select just one activity) (drop-down choice of all arts activities reported by the respondent in section 2); Q3. Why does this activity make you feel connected to other people? Please write in as much detail as possible and include examples or stories where appropriate (open response).

Ethical approval for the research was granted by the Conservatoires UK Research Ethics Committee (CUK REC) on 16 February 2019. All methods were performed in accordance with CUK REC and British Psychological Society (BPS) guidelines and regulations, and respondents gave informed consent to participate. Links to support (e.g., for mental health) were provided at the end of the survey.

\section{Respondents}

UK-based respondents were recruited to complete the HEartS Survey through an online data collection platform, Qualtrics, over a period of 6 months between March and August 2019. Data collection quotas were set for gender, age, geographical region, ethnicity, and education following the overall distributions of these key sociodemographic variables in the UK 2011 Census [56].
A total of 11861 respondents started the survey. Of these, 1623 did not consent to participate in the survey and stopped at the consenting process. A further 3219 respondents were excluded after answering initial sociodemographic questions as the quotas for their characteristics were already reached. A further 969 were excluded due to completing the survey in under four minutes (i.e., speeding through the survey, $n=97$ ) or providing nonsense or abusive responses to open questions $(n=872)$ [56]. Of the remaining 6050 participants, 5892 answered Q1 above and therefore constitute the sample for this study. All respondents who completed the survey were paid a modest fee via the Qualtrics platform.

Full sociodemographic characteristics are detailed in Supplementary Table 1 . Respondents were adults living in the UK aged 18-25 (13\%), 26-35 (21\%), 36-45 (17\%), 46-55 (15\%), 56-65 (17\%), 66-75 (14\%), and 76-94 (2\%) years. $51 \%$ of respondents identified as women. $89 \%$ identified as White British or Irish, or other White background, $5 \%$ as Asian ethnic backgrounds, $2 \%$ as Black ethnic backgrounds, 2\% as Mixed ethnic backgrounds, and $1 \%$ as any other ethnic background. Respondents lived across regions in the UK, with the largest group (27\%) living in London or the South East. 4\% had no formal educational qualifications, $12 \%$ other vocational and foreign qualifications, 26\% GCSE, O Level, AS level, and NVQ Level 1-2 qualifications, 23\% A level, baccalaureate, and NVQ Level 3 qualifications, and 36\% university degree and NVQ Level 4-5 qualifications. $20 \%$ of respondents lived alone, $35 \%$ with a partner only, $29 \%$ with children (with or without a partner), and 15\% with family, house share, or other. The final sample matches the national profile closely in terms of sociodemographic and economic characteristics, but both the rates of loneliness (46\%) and depression (78\%) in this sample are higher than those in the general population. As discussed elsewhere, this may be connected to the nature of the non-probability, online survey [56].

\section{Analysis}

Descriptive statistics using quantitative data for RQ1 and RQ2 are reported below. Further analyses from the HEartS Survey are documented elsewhere [56]. Analysis of qualitative data for RQ3 (excluding those who answered 'no' to whether the arts connected them to others or provided nonsense responses, leaving $n=4352$ ) was conducted in NVivo, following an inductive thematic analysis that proceeded in five-steps. First, $10 \%$ of the data for each art form selected in Q2 were analysed by one author (AMB) to identify codes salient to RQ3. This analysis was inductive and cross-checked by another author (RP). Second, the agreed coding scheme was applied to another $40 \%$ of the data by AMB, with codes grouped into suggested sub-themes and themes. 
The coding and the grouping were cross-checked by RP, resulting in reassignment of some codes and relabelling or regrouping of some of the sub-themes and themes. Third, the revised coding scheme was applied to the remaining $50 \%$ of the data by AMB. Fourth, the pre-final coding and groupings were cross-checked by RP before $\mathrm{RP}$ and AMB agreed the final set. Finally, this final set were cross-checked by a third author (UT).

\section{Results}

To what extent do adults perceive a link between their arts engagement and feelings of social connectedness? (Q1)

Of the sample of 5892, 4785 (82\%) reported that arts engagement made them feel socially connected, as summarised in Table 1. 35\% reported that this occurred a little, $17 \%$ around half of the time, $22 \%$ often, and $8 \%$ always.

\section{Which forms of arts engagement are most reported as} linked with feelings of social connectedness? (Q2)

Table 2 summarises the arts and cultural activities identified by respondents as most linked with feelings of social connectedness. The top three activities identified were attending a live music performance $(n=1265$, $26 \%)$, watching a live theatre performance $(n=465$, $10 \%)$, and watching a film or drama at the cinema or other venue $(n=455,10 \%)$.

How is arts engagement perceived to facilitate feelings of social connectedness? (Q3)

The qualitative analysis revealed 4687 codes organised into four key themes, comprised of 12 sub-themes and, where required, five sub-sub-themes (see Table 3). For each sub-theme, the evidence is discussed with indicative quotations selected from across the range of art forms. Supplementary Table 2 presents the number of citations across each form of arts engagement for each sub-theme and sub-sub-theme, supported by indicative evidence.

Table 1 The extent to which adults in the UK perceive a link between their arts engagement and feelings of social connectedness

\begin{tabular}{lll}
\hline $\begin{array}{l}\text { Does your engagement with the arts and cultural } \\
\text { activities you have told us about today help you } \\
\text { to feel connected with other people? }\end{array}$ & Number & Percent \\
\hline not at all & 1107 & 19 \\
a little & 2039 & 35 \\
around half of the time & 997 & 17 \\
often & 1289 & 22 \\
always & 460 & 8 \\
\hline
\end{tabular}

Table 2 Forms of arts engagement most linked with feelings of social connectedness

Of the arts and cultural activities you have told us Number Percent about, which makes you feel most connected to other people?

\begin{tabular}{|c|c|c|}
\hline Been to a live musical performance & 1265 & 26 \\
\hline Watched a theatre performance live & 465 & 10 \\
\hline $\begin{array}{l}\text { Watched a film or drama at a cinema or } \\
\text { other venue }\end{array}$ & 455 & 10 \\
\hline Read as a past-time activity & 336 & 7 \\
\hline $\begin{array}{l}\text { Been to an exhibition, museum, or collection } \\
\text { of art, photography, sculpture/other arts }\end{array}$ & 267 & 6 \\
\hline Played a musical instrument or sang & 262 & 6 \\
\hline Deliberately listened to recorded music & 226 & 5 \\
\hline Listened to audio books or podcasts & 198 & 4 \\
\hline $\begin{array}{l}\text { Attended a book club where people meet } \\
\text { to discuss and share books }\end{array}$ & 170 & 4 \\
\hline $\begin{array}{l}\text { Been to an event connected with books or } \\
\text { reading }\end{array}$ & 146 & 3 \\
\hline Done any form of crafts & 144 & 3 \\
\hline $\begin{array}{l}\text { Been to street art, public art displays, admired } \\
\text { architecture or an historical monument }\end{array}$ & 134 & 3 \\
\hline $\begin{array}{l}\text { Done photography, film, video making, or other } \\
\text { related pursuits as a past-time activity }\end{array}$ & 132 & 3 \\
\hline Written as a past-time activity & 101 & 2 \\
\hline $\begin{array}{l}\text { Practised, rehearsed, or performed dance as a } \\
\text { past-time activity }\end{array}$ & 96 & 2 \\
\hline $\begin{array}{l}\text { Done painting, drawing, printmaking, sculpture, } \\
\text { or other related pursuits }\end{array}$ & 82 & 2 \\
\hline Written or created music & 74 & 2 \\
\hline $\begin{array}{l}\text { Practised, rehearsed, or performed a play, } \\
\text { drama, opera, musical theatre, circus skills }\end{array}$ & 65 & 1 \\
\hline Watched a dance performance live & 63 & 1 \\
\hline $\begin{array}{l}\text { Been to a convention, show, or fair relating to } \\
\text { crafts or decorative arts }\end{array}$ & 63 & 1 \\
\hline Other & 41 & 1 \\
\hline
\end{tabular}

\section{Theme 1: facilitating social opportunities}

The first theme reflects how the arts facilitate social opportunities. Sub-theme 1.1 focuses on how the arts provide opportunities to meet new people:

It's lovely to meet new people and mutually share perspectives [been to an exhibition, museum, or collection of art].

[Because] anyone can come there you meet a lot of nice and interesting people [street art, public art, architecture, historical monument].

It is sociable and a good way of meeting people [practised, rehearsed, or performed dance].

As well as meeting new people, the arts were also identified as a means of forging new friendships: 
Table 3 Summary of themes for how arts engagement is perceived to facilitate feelings of social connectedness

\begin{tabular}{|c|c|}
\hline Themes and (sub)sub-themes & Description \\
\hline 1. Facilitating social opportunities & The arts facilitate social opportunities \\
\hline 1.1 Meeting new people & The arts provide opportunities to meet new people and to make new friends \\
\hline 1.2 Socialising and interacting with others & The arts encourage and facilitate generalised social interactions \\
\hline 1.2.1 Conversing about art & The arts can act as a catalyst for conversations \\
\hline 1.2.2 Negating pressures of social interaction & The arts facilitate interaction and connection without pressures of social situations \\
\hline 2. Facilitating sharing & The arts facilitate opportunities for shared experiences \\
\hline 2.1 Sharing experiences & The arts act as a shared experience creating bonds between those involved \\
\hline 2.1.1 Sharing emotions & The arts allow people to share emotional responses and to express feelings \\
\hline 2.1.2 Sharing art with others & $\begin{array}{l}\text { When artists share their art, it creates a sense of connection between them and } \\
\text { their audience }\end{array}$ \\
\hline 2.2 Shared purpose & The arts provide people with a sense of shared purpose \\
\hline 3. Facilitating commonality and belonging & The arts facilitate feelings of similarity and belonging \\
\hline 3.1 Being part of something & $\begin{array}{l}\text { The arts allow people to feel part of, and belonging to, something bigger than } \\
\text { themselves }\end{array}$ \\
\hline 3.1.1 Enabling proximity to others & The arts elicit feelings of direct and indirect proximity with other people and times \\
\hline 3.2 Connecting through common interests & The arts connect people with common interests, specific to the arts activity \\
\hline 3.3 Connecting with likeminded people & $\begin{array}{l}\text { The arts connect people with common tastes and opinions, regardless of the arts } \\
\text { activity itself }\end{array}$ \\
\hline 4. Facilitating collective understanding & The arts facilitate learning from and about other people \\
\hline 4.1 Learning from and with others & The arts allow people to learn new skills and knowledge from and with others \\
\hline 4.2 Relating to others & The arts allow people to relate to others \\
\hline 4.3 Learning about others & The arts provide a means of learning about other people, places, and times \\
\hline 4.4 Connecting with different people and cultures & $\begin{array}{l}\text { The arts expose people to different cultures and bring together people from } \\
\text { different backgrounds }\end{array}$ \\
\hline 4.5 Connecting with different viewpoints & The arts expose people to different viewpoints and opinions \\
\hline
\end{tabular}

Once I went to a music festival and I ended up with many newfound friends as we had similar music tastes [live musical performance].

It's actually how I met most of my friends. I was in the school library drawing when a group of four people with sketchbooks came up to me and started complimenting my work. We kept talking and now we're all best friends [painting, drawing, printmaking]. I've been interested in photography since I was about five, when I played around with my Dad's camera and took pictures of random things, myself and my parents. Ever since then I've been getting better cameras, getting more skilled at my interest and job, and have made lots of life-long friends due to it [photography, film, videomaking].

Linked with meeting new people and making friends, the arts were also reported to encourage and facilitate general social interactions (sub theme 1.2):

It brings everyone together as a social event. It's a good opportunity to chat and build relationships with others [book or reading event].
We can appreciate the music together and we talk and hang out and generally have fun [live musical performance].

It's a knitting group with a wide age range. The founder set it up as a group to help with mental health issues. It's sociable, inspirational and makes what could be a solitary pastime into one to be shared [crafts].

In addition to general social interaction such as being with or talking with others, the arts were also identified as a specific catalyst for conservations (sub-sub-theme 1.2.1):

It gives me the opportunity to converse with other people, to exchange ideas and review conceptions [book club].

Admiring things with people and going to museums sparks conversation which helps me to connect [been to an exhibition, museum, or collection of art].

Street entertainment seems to create camaraderie between strangers, especially when it is unexpected and catches people by surprise. The public will often discuss what is going on with those around 
them, even if they have never met each other before [street art, public art, architecture, historical monument].

Finally, for a very small sub-set of the sample, the arts - particularly live music - facilitate interaction and/or connection while negating or mitigating some of the pressures of social interaction that they would otherwise experience (sub-sub-theme 1.2.2):

[I] get to enjoy the company of friends without having to worry about chatting and doing anything the whole time as you have something to watch [watched a theatre performance].

You can be together without having to engage with anyone and still share in the music and the feeling [live musical performance].

I am a mother of a large family. However, I consider myself a loner. Going to museums and such, when I am alone, makes me feel connected to the people who created the pieces. It's akin to having a silent conversation with the artist. I enjoy this [exhibition, museum, or collection of art].

In sum, the first theme captures how the arts facilitate social opportunities including meeting new people and making new friends, encouraging general social interactions, catalysing conversations, and supporting feelings of connection for people who otherwise experience challenges with social interaction.

\section{Theme 2: facilitating sharing}

The second theme reflects how the arts facilitate opportunities for shared experiences. The first sub-theme concerns the sharing of experiences (sub-theme 2.1), with the arts acting as a shared experience that creates bonds between those involved:

The performance makes me feel more connected to people, like we're sharing something [live musical performance].

It is the shared sense of witnessing something. It gives it a certain sense of permanence, and timelessness. Going to see something as evocative and inspiring as the reclining Buddha in Bangkok makes you think of all the other people that have stood where you are. It makes you contemplate how they felt. It gives you a far greater depth of perception and to my mind increases your human consciousness [street art, public art, architecture, historical monument].

Cinema is a shared experience despite being in the dark and not having contact with anybody [watch a film or drama at a cinema or other venue].
In addition to the more general sense of the arts being a shared experience, two sub-sub-themes further illuminate this idea. First, that the arts allow people to share emotions (sub-sub-theme 2.1.1):

When the play ends [it] is like you were not alone feeling all those things [watched a theatre performance].

Sometimes a particular song might come on and you can see the meaning it has to thousands of other people not just yourself so you're no longer alone [live musical performance].

Other people can feel what I feel when I wrote poems [written as a past time activity].

Of note is that the arts elicit shared emotional responses, but also that they facilitate sharing of emotions. Second, when people share their own art, they experience a sense of connection between themselves and their audience (sub-sub-theme 2.1.2):

It makes me feel connected as I like to show my creations off and talk about them like my most recent make of an ashtray made out of a can that I got a few compliments on [crafts].

I feel the images I produce can be looked at others and interpreted in whatever they see fit and it gives me joy knowing my work is looked upon by others and they take something away from it [done photography, film, videomaking].

When I play for people I can see it in their faces what they are feeling and it's the connection through my music that has allowed that to happen [played a musical instrument or sang].

Finally, sub-theme 2.2 highlights how the arts can provide people with a sense of shared purpose:

I am in a place with lots of different people all there for the same reason, to appreciate the performance and share the same moment [watched a theatre performance].

We are all on the same wavelength. A desire to paint better [painting, drawing, printmaking].

As well as the shared purpose of engaging in the activity, this sub-theme also captures wider shared purposes, connected with giving to or supporting others:

I live in a sheltered housing complex and we meet once a week to knit and crochet items which are then sold to raise funds, or given to a charity organisation [crafts].

Working to a common goal, give unity. Supporting 
and encouraging one another. It helps to bring the best out in people [practised, rehearsed or performed in a play, opera, etc.].

In sum, the second theme captures how arts provides people with shared experiences, including shared emotions, connections between artist and audience, and a sense of shared purpose.

\section{Theme 3: facilitating commonality and belonging}

The respondents identified that arts engagement, particularly live music and theatre, allows them to feel part of something bigger than themselves (sub-theme 3.1). This is first reflected in feeling part of something, such as an event or atmosphere:

It normally involves large numbers of people and you feel you're part of one single organism opposed to just alone. It puts you in the zone and you feel a connection with those around you [live musical performance].

Book clubs make me feel incredibly connected with those around me as due to the vibrance [sic] in the actual books makes me potentially feel interconnected with the book and my surroundings [attended a book club].

Watching a film with others we all enjoyed at a drivein movie surrounded by likeminded people all singing along in their own cars was really enjoyable and made me feel part of the experience [watch a film or drama at a cinema or other venue].

As well as being part of an atmosphere or event, this sub-theme is also connected to the idea of 'belonging' as part of a wider community:

I read, watch videos and do searches about it online and through social media, and through this I have seen that there are many people that like me like arts and crafts and also are similar to me in other aspects, which I didn't know before. Usually I don't really manage to connect in meaningful ways with others because I feel and am perceived as too different from the people I am around. So even though I have not really personally connected to the arts and crafts people, I feel as part of the community and I have hope that when I feel ready I will be able to join said community in a more active way [crafts]. Rehearsing a play demands that you connect with your fellow performers. We aim to invoke emotion in our audience and so we have to connect with each other in order to feel those emotions ourselves. It's a deeply collaborative process, one which cannot achieve its full potential without connecting with each other. Even outside of rehearsals, you become a team - a family, even. It's a wonderful feeling of belonging [practised, rehearsed, or performed in a play, opera etc.]. I play in the village Brass band. You feel like a team and a vital part of the community [played a musical instrument or sang].

Within this sub-theme, the arts were also perceived as a way of being near to other people and times (sub-subtheme 3.1.1):

Being [in] a room full of people surrounded by art and just appreciating it [been to an exhibition, museum, or collection of art].

Listening to music that I listened to in the [19]60s makes me feel connected to all my friends I went dancing and going to concerts with in my youth [listened to recorded music].

It's the only time I get a chance to spend time with family and friends so it's a great activity to do with people [watch a film or drama at a cinema or other venue].

Of note is that this proximity could either be direct (i.e., nearness to others, spending time with others) or indirect (i.e., closeness to other times and to people, including oneself, in the past).

The second and third sub-themes reflect how the arts facilitate feelings of similarity between people. Subtheme 3.2 captures how the arts, particularly live music, connect people with common interests specific to particular arts activities:

Literature is my greatest love so when I'm at a literary event I feel like I'm in the sort of company that constitutes 'my tribe' in the world, the people with whom I have the most in common [been to a book or reading event].

I feel that when I'm at a craft fair other people are as interested as me therefore we have a connection [been to a crafts convention or show].

It makes you feel connect[ed] as there are so many likeminded people there with you who obviously share a love of the band's music and know as much about them as I do and you feel like you belong to a club [live musical performance].

For some participants, the shared common interests provide a means of connection that might otherwise not feel possible, a finding mirroring sub-sub-theme 1.2.2 (negating pressures of social interaction):

I'm quite an awkward person while meeting new people but as soon as I meet another dancer it's like 
I feel instantly connected to them because we have something in common! And when I dance with someone new it's like magic on the stage because I'm doing what I love with someone who loves it too! Nothing makes me feel more connected to a person then dancing with them does! It's a truly special feeling [practised, rehearsed, or performed dance].

As well as connecting people with arts-specific common interests, sub-theme 3.3 reflects how the arts bring like-minded people - with common tastes, opinions, and beliefs - together more generally:

I play in the worship team at my local church and the time of worship is a coming together of likeminded people, praising God. So we do feel connected with each other [played a musical instrument or sang].

I think how someone connects with a story/character says a lot about them and I like to engage with people who feel the same way towards a certain story/ character as I do [read].

I went to the theatre to see a drag queen. Everyone in the audience was accepting and likeminded which made me feel more connected to others [watched a theatre performance].

In sum, the third theme captures how the arts facilitate feelings of commonality and belonging, including through being part of an event or activity, feeling a sense of belonging, being close to others, and through the sharing of arts-specific shared interests and connections with likeminded people.

\section{Theme 4: facilitating collective understanding}

The fourth theme focuses on the ways in which the arts facilitate learning from and about other people in ways that foster social connections. Sub-theme 4.1 reflects how the arts, particularly crafts, allow people to learn new skills and knowledge with and from others:

My sister and I went to a pottery class last month, and as well as learning new techniques together, we managed to catch up, give each other advice, and take a keepsake of our special day [crafts].

I work alongside others and can throw ideas and solutions at each other. They make me better and I make them better. We complement each other [done photography, film, videomaking].

The connection when someone enjoys the same books that you do and when your child takes an interest in some of them and asks that you read them at bedtime, then starts asking questions about the content because they're taking it all in and want to understand it all better. It's all heartwarming, and the world suddenly feels a little less lonely [read].

Linked to this, sub-theme 4.2 illustrates how the arts allow people to relate to others:

I suppose it's usually when the speaker or author is someone I admire or respect. Often their experiences and what they write about reflect my own experiences and I feel less alone [been to a book or reading event].

Relating to their stories. Makes me feel like I'm not alone. Sharing stories. Help feel normal [listened to audiobook or podcast].

It stops you feeling so alone, when someone else can describe a situation the same way you experience it [read].

Of particular note here is that the arts do not need to be 'in person' to offer opportunities for relating to others. In fact, the three examples shown here illuminate how the arts facilitate connections at an emotional and experiential level, allowing for relatedness through the artistic product.

Additionally, the arts, particularly reading, facilitate a means of learning about other people, places, and times (sub-theme 4.3):

Being outside and exploring with someone particularly if it has a historical interest where you can feel connected to the people before us [been to an exhibition, museum, or collection of art].

I feel I connect with other people through photography. I get to spend time with people. Listen to their stories. I try to capture their emotions, what they've been through and what they are currently going through [done photography, film, videomaking].

The podcasters are talking about something that interests both them and me. Listening to the same podcasters regularly makes me feel like I am getting to know them [listened to audiobook or podcast].

It opens up new worlds and new ideas. It helps me to understand the lives and experiences of other people [read].

Here, we see the arts connecting people directly (e.g., through photography) but also indirectly, such as through podcasts or books, or through connecting to people from other times through an artistic activity.

The final two sub-themes within this theme illustrate how the arts foster connections through differences. Subtheme 4.4 captures this in respondents' descriptions of 
how the arts expose people to different cultures, bring together people from different backgrounds:

They usually involve people from various backgrounds, of different ages but all with a love of music in common so instil a sense of common ground, no matter the otherwise diversity of the attendees [been to a live musical performance].

You get such a variety of people at art venues of museums, all sharing an experience which makes me feel like part of the wider world [been to an exhibition, museum, or collection of art].

A shared love of music, sometimes a specific type, shows that regardless of age or other interests, there is a common bond that can be explored ... [It] may make someone realize that people who may seem very different, may not be so different after all [listened to recorded music].

Here, we see social connectedness linked with being 'part of the wider world' through exposure to diversity. Linked with this, sub-theme 4.5 captures how the opportunity to be exposed to different viewpoints and opinions was also expressed as connecting:

It gives you a chance to see other perspectives and hear new ideas, seeking those things out is one of the most human things you can do [attended a book club].

This makes me think about how other people interpret and see things. It makes me see how we can see things differently. Like an abstract sculpture can be seen to appear very different to me than the person who created it, however I feel connected as we can both see something united [been to a crafts convention or show].

I find drawing and painting a relaxing and rewarding experience whether alone or as member of a group. It is amazing that a number of people can draw or paint a specific scene or object but their interpretation will appear different in almost every case and can become the topic of in depth conversation [done painting, drawing, printmaking].

In sum, the fourth sub-theme captures how the arts facilitate learning from and about other people, building social connectedness through learning from and with others, relating to others, learning about others, connecting with different people and cultures, and connecting with different viewpoints.

\section{Discussion}

This article has addressed three research questions pertinent to the role of the arts in facilitating social connectedness for public social health. The first question related to the extent to which adults in the UK perceive a link between their arts engagement and feelings of social connectedness. Our findings show that over $80 \%$ of the respondents reported that their engagement in the arts makes them feel socially connected at least 'a little'. This finding is expected given the previously cited evidence that the arts can support social connections, although the evidence base to date has been most extensive in research with older adults [17-20]. This study extends the evidence base through a wider sample, based on key demographics of the adult UK population and representing a much wider range of adult age groups.

The second question focused on which forms of arts engagement are most reported as linked with feelings of social connectedness. While previous research has tended to focus on certain arts activities - notably museum/gallery attendance [21-23] and music [25, 28-30] - the current study demonstrates a wider range of activities that respondents report connects them socially to others. Both live musical performance and visiting an exhibition, museum, or gallery were among the top five listed activities, but these sit alongside activities less reported in the existing literature including live theatre performance, watching a film or drama at the cinema, and reading. As well as expanding the range of arts activities that can be seen as socially connecting, these findings emphasise that it is not only participatory activities - those where a participant makes or creates art themselves - that achieve this connection. This is an important finding, given that existing evidence based on intervention studies often focuses predominantly on participatory activities, such as choral singing [31], dance [38], and textile crafting [40]. Here, the activities reported as most connecting were more 'receptive', undertaken - with the exception of reading - at arts venues outside of the home. The implications of this in light of the COVID-19 pandemic are important, as activities such as concerts, theatre productions, and cinema screenings have been closed or reduced. Further research will be required to identify whether and how the arts support social connections during and after the COVID-19 pandemic.

The third research question focused on how arts engagement is perceived to facilitate feelings of social connectedness. To answer this, we conducted a large-scale qualitative analysis of data that resulted in four overarching themes: the arts support social connections through facilitating social opportunities, facilitating sharing, facilitating commonality and belonging, and facilitating collective understanding. The first theme - social opportunities - speaks to the ways in which the arts can support or enhance social networks. This includes 
explicitly extending social contacts through meeting new people and making new friends, but also opportunities simply to interact with other people, either in general or through specifically discussing an arts activity. In this theme we see overlaps with what Wang and colleagues refer to as 'network quantity' in their work on social isolation in mental health, or in other words 'the number of people in someone's social network, [the] number or frequency of someone's social contacts over a period of time' [62]. Of particular note here are the sub-subthemes conversing about art (1.2.1) and negating pressures of social interaction (1.2.2). Both imply the role that the arts can play in providing a catalyst for social interaction (e.g., having a conversation) but also a means of connecting with others that can be experienced as more accessible or less pressured than 'typical' social interaction (e.g., being able to have a 'silent conversation'). Indeed, the non-verbal nature of some forms of arts engagement has been highlighted in other research as important for connecting people [27].

The second theme - facilitates sharing - encapsulates the ways in which respondents reported that arts engagement leads to shared experiences. This links with Hare-Duke and colleagues' conceptual framework for social connectedness in mental disorders, and in particular their dimension of 'closeness' [15], or feeling close to other people. This closeness appears to be facilitated by the shared experienced of an arts activity itself (e.g., sharing a cinema screening) but also by feelings of shared purpose and emotions. Given that loneliness is emotional as well as social [2], it may be that arts engagement supports feelings of social connection through facilitating emotional closeness and feelings of emotional intimacy with other people.

In the third theme, the arts emerged as a means of eliciting feelings of commonality and belonging, a finding echoed in O'Rourke and Sidani's operationalization of social connectedness [13]. Indeed, that the arts can support a sense of belonging is highlighted by other research [27, 33, 63-68]. This theme also highlighted the importance of being near to other people, either directly (e.g., in person) or indirectly (e.g., feeling connected to old friends when listening to certain pieces of music), making the important point that connection through the arts does not require people to be physically together. For some respondents, the notion that others had or could engage with the same art form could also instil feelings of social connections. This finding is mirrored elsewhere, with museum attendees voicing that they felt connected to others who may have viewed the same museum exhibits [69]. Similarly, it has been previously suggest that arts engagement can reduce feelings of loneliness through acting as a social surrogate [32, 33, 70]. Therefore, not only can the arts provide social connections despite an absence of physically proximity to others, but they may also enable people to create the concept of another person to whom they feel connected. Finally, this theme related to 'being at one' through, for example, singing together as part of the audience at a live music performance. We can see a link here with previous evidence that singing, for example, can promote fast cohesion among people who are not familiar with one another [29], a point reinforced by the ways in which respondents in this study reported feeling 'at one' with others in large audiences.

This third theme also focused on how arts engagement can elicit feelings of commonality between people, evident through the arts connecting people with common interests, tastes, and opinions. The dimension of 'identity and common bond' identified by Hare-Duke and colleagues is relevant here: 'believing that one shares important characteristics with other people or members of a group' [15], as well as their notion of 'social acceptance', or the 'perception of being an accepted member of a particular group or community' [15]. Indeed, theories of social identity posit that people's personal identification with social groups are important for health [71], more so than social contact [72]. The arts have been shown to create this sense of social identity, or group identification, in this study and elsewhere [73, 74]. Of note is that social identity in this study emerges as both directly related to an arts activity (sub-theme 3.2) but also as wider than the arts activity itself (sub-theme 3.3), again demonstrating how the arts can support social connections both directly and indirectly.

Finally, the fourth theme - facilitating collective understanding - reflects how the arts supports social connections through allowing people to learn from and about other people. This includes 'valued relationships' [15] including learning new skills with others, and learning about others. This finding echoes the ideas of Maidment and Macfarlane (2009), who discuss how reciprocity of learning with others in a crafts club enhanced social connectedness [75], linking this with Siegrist et al.'s concept of 'social productivity', where people spend effort supporting others in socially valued activities [76]. Of particular note here are the two subthemes that reflect feelings of connection through difference, either by connecting with different people and cultures, or through connecting with people who hold different viewpoints. These are perhaps the most unique among the sub-themes, illuminating how the arts bring together people who may be different to one another, but who share an interest in the same activity. This can lead to connection through, for example, giving a sense of being part of the 'wider world', through a realisation that people whom we think of as different may in fact not be so different, and through exposure to different 
opinions and ideas on the same arts activity. Indeed, researchers have highlighted that, while museums have historically promoted specific ideologies, they can also act as safe spaces where members of communities can share a diversity of opinions and be exposed to other cultures [77-79]. Furthermore, exposure to the arts has also been shown to increase levels of tolerance to other viewpoints, with research finding that, through discussing works of art, medical students could develop an ability to accept multiple interpretations and increase their levels of empathy [80]. This article extends these findings beyond viewing artworks and visiting museums, with arts activities including attending book clubs, engaging in photography, and listening to audiobooks enabling users to feel a connection to others with differences of opinions. As a result, the arts may act as 'deliberative spaces', ideal environments where individuals 'can discuss and debate common concerns, access a wide range of information, and reflect and revise their understanding of issues' [81].

Taken together, the four themes and their sub-themes present a complex account of how arts engagement can support social connectedness, as presented in Fig. 1. Two points are of note. First, the ways in which the arts support social connections should be understood as complex. This complexity is evident not only in the breadth of sub-themes, which illustrate wide ranging means of social connection through the arts, but also in the overlap between themes and between sub-themes. Many of the survey responses were coded to multiple codes in the first step of the analysis, meaning that respondents were identifying multiple points of connection in their responses. It should not therefore by inferred that an arts activity facilitates one form of connectivity only, but rather that multiple forms of connectivity can occur simultaneously. Second, respondents were asked to write about the activity they felt most connected them to other people. This means that the evidence presented in this study focuses on the 'optimal' connective properties of the arts, and that it is specific to a particular activity as selected by individuals. It is not the case that all arts activities will facilitate all four modes of connection, and it should be assumed that the choice of arts activity and the ways in which it supports connection (or not) are both highly idiosyncratic within and between individuals. In music, for example, a recent meta-ethnography [82] made explicit the importance of taking into account individual needs within specific individual circumstances when understanding how participatory music engagement supports mental wellbeing, and the same is likely to be the case with understanding how the arts support social connectedness.

\section{Conclusion}

Given that loneliness is linked to mortality as well as poorer physical and mental health outcomes [4-6], finding ways to prevent or reduce it is important for social public health. Social connectedness has been proposed as a means of reducing loneliness [15], focusing attention on what people can do to build meaningful social connections [14]. This article has demonstrated that, in a large sample matched to key demographic characteristics of the UK population, over $80 \%$ of respondents reported that arts engagement makes them feel connected to others, particularly live music performance, theatre performance, watching a film or drama at the cinema or other venue, reading, or attending exhibitions, museums, or galleries. This evidence suggests that people at risk of or experiencing loneliness can be directed towards arts activities as a potential means of developing social connections. It also reinforces the evidence base on the role of the arts in health and wellbeing [83], reminding us of the potential health implications of the current COVID-19 pandemic which has shut arts venues, prevented professional

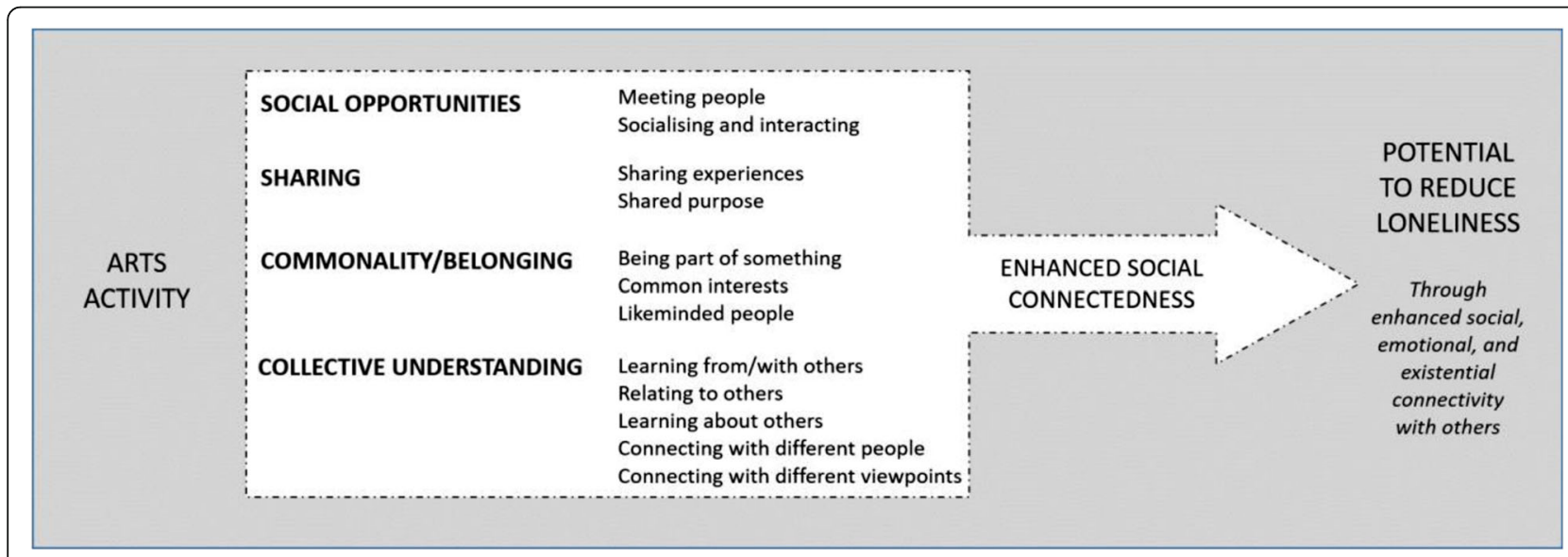

Fig. 1 How arts engagement is perceived to facilitate feelings of social connectedness 
and amateur arts activities, and forced a skills exodus from the arts profession. Further research will be required in order to understand how people have used the arts to connect with others since the start of the COVID-19 pandemic, and how this has changed as the situation has developed. Finally, in exploring how the arts can support social connections, the findings have presented a rich tapestry of pathways. These speak to social connections that have the potential to mitigate emotional, social, and existential loneliness $[2,3]$, and provide evidence for those looking to commission arts activities that enhance social connectedness as well as those who design and deliver them.

This research is limited, first, by an inherent bias in the sample, in that all respondents providing a response to the three included survey questions had, previously in the survey, already identified that they engaged in arts activities at least once in the past 12 months. Further, levels of loneliness and depression were higher than expected in the sample, potentially influencing the ways in which respondents reflected on their use of the arts for social connectedness. Second, the analysis process was by necessity interpretative. To add validity the themes were cross-checked by two authors at three time points during the analysis process (10, 50, and 100\%) and the final overarching themes and sub-themes were agreed by three authors. Working with such a large qualitative dataset was resource heavy, but saturation was taken to only be achieved once all possible perspectives were included, a point reinforced by some of the smaller yet still pertinent sub-sub-themes. Third, the data were limited by the mode of response in the survey, which was 'one-time' and anonymous. While this did not allow for any clarification or probing of respondents' answers, nor for further exploration with those who reported that their arts engagement was not associated with feelings of social connectedness, it did allow for large-scale qualitative data collection in an efficient manner. The collection and analysis of 'big qual' [84] data in the field of arts and health is important as a means of understanding the complexity of how large groups of people engage with the arts and how this interacts with their perceived health. In adopting this approach here, this article provides robust evidence of how the arts support social connectedness among a large sample of adults in the UK.

\section{Supplementary Information}

The online version contains supplementary material available at https://doi. org/10.1186/s12889-021-11233-6.

Additional file 1.

Additional file 2.

Acknowledgements

Not applicable.

\section{Authors' contributions}

$\mathrm{RP}, \mathrm{AMB}, \mathrm{UT}, \mathrm{NS}, \mathrm{KG}$, and $\mathrm{AW}$ contributed to study conception and design. $A M B, R P, U T$, and NS conducted the analyses. RP and AMB led the drafting of the manuscript, to which UT, NS, KG, and AW contributed. All authors approved the final manuscript.

\section{Funding}

The research reported in this article was supported by HEartS, a project funded by the United Kingdom's Arts and Humanities Research Council (AHRC) to investigate the health, economic, and social impact of the arts (Grant ref. AH/P005888/1) and by The Loneliness and Social Isolation in Mental Health Research Network, funded by UK Research and Innovation (Grant ref. ES/S004440/1). The funders had no role in the design of the study, collection, analysis, and interpretation of data, or in writing the manuscript.

\section{Availability of data and materials}

The datasets used and/or analysed during the current study are available from the corresponding author on reasonable request.

\section{Declarations}

Ethics approval and consent to participate

Ethical approval for the research was granted by the Conservatoires UK Research Ethics Committee (CUK REC) on 16 February 2019. All methods were performed in accordance with CUK REC and British Psychological Society (BPS) guidelines and regulations and respondents gave informed consent to participate.

Consent for publication

Not applicable.

\section{Competing interests}

The authors declare that they have no competing interests.

Received: 19 February 2021 Accepted: 27 May 2021

Published online: 24 June 2021

\section{References}

1. Victor $C$, et al. An overview of reviews: the effectiveness of interventions to address loneliness at all stages of the life-course. What Works Wellbeing. 2018. p. 1-87.

2. Weiss R. Loneliness: The experience of emotional and social isolation. Cambridge: MIT Press; 1973.

3. Bolmsjö I, Tengland P-A, Rämgård M. Existential loneliness: an attempt at an analysis of the concept and the phenomenon. Nurs Ethics. 2019;26(5):131025. https://doi.org/10.1177/0969733017748480.

4. Cacioppo JT, Cacioppo S. The growing problem of loneliness. Lancet. 2018; 391 (10119):426. https://doi.org/10.1016/S0140-6736(18)30142-9.

5. Holt-Lunstad J, Smith TB, Baker M, Harris T, Stephenson D. Loneliness and social isolation as risk factors for mortality: a meta-analytic review. Perspect Psychol Sci. 2015;10(2):227-37. https://doi.org/10.1177/1745691614568352.

6. Leigh-Hunt N, Bagguley D, Bash K, Turner V, Turnbull S, Valtorta N, et al. An overview of systematic reviews on the public health consequences of social isolation and loneliness. Public Health. 2017;152:157-71. https://doi.org/10.1 016/j.puhe.2017.07.035.

7. Victor CR, Yang K. The prevalence of loneliness among adults: a case study of the United Kingdom. J Psychol. 2012;146(1-2):85-104. https://doi.org/10.1 080/00223980.2011.613875.

8. Meltzer H, Bebbington P, Dennis MS, Jenkins R, McManus S, Brugha TS. Feelings of loneliness among adults with mental disorder. Soc Psychiatry Psychiatr Epidemiol. 2013;48(1):5-13. https://doi.org/10.1007/ s00127-012-0515-8.

9. Ingram I, Kelly PJ, Deane FP, Baker AL, Goh MCW, Raftery DK, et al. Loneliness among people with substance use problems: a narrative systematic review. Drug Alcohol Rev. 2020;39(5):447-83. https://doi.org/1 $0.1111 /$ dar. 13064 .

10. Lasgaard M, Friis K, Shevlin M. "Where are all the lonely people?" A population-based study of high-risk groups across the life span. Soc Psychiatry Psychiatr Epidemiol. 2016;51(10):1373-84. https://doi.org/10.1007/ s00127-016-1279-3. 
11. Victor C. Interventions to combat loneliness for older adults: a review of reviews. Innov Aging. 2018;2(suppl_1):964. https://doi.org/10.1093/geroni/ igy031.3571.

12. Lee RM, Robbins SB. Measuring belongingness: the social connectedness and the social assurances scales. J Couns Psychol. 1995;42(2):232-41. https:// doi.org/10.1037/0022-0167.42.2.232.

13. O'Rourke HM, Sidani S. Definition, determinants, and outcomes of social connectedness for older adults: a scoping review. J Gerontol Nurs. 2017; 43(7):43-52. https://doi.org/10.3928/00989134-20170223-03.

14. Morgan, T. et al. Social connectedness: what matters to older people? Ageing Soc. 1-19 (2019) doi:https://doi.org/10.1017/S0144686X1900165X.

15. Hare-Duke L, Dening T, de Oliveira D, Milner K, Slade M. Conceptual framework for social connectedness in mental disorders: systematic review and narrative synthesis. J Affect Disord. 2019;245:188-99. https://doi.org/10.1 016/j.jad.2018.10.359.

16. What Works Wellbeing. Briefing; What do we know about tackling loneliness. (2018).

17. Dadswell A, Wilson C, Bungay H, Munn-Giddings C. The role of participatory arts in addressing the loneliness and social isolation of older people: a conceptual review of the literature. J Arts Communities. 2017;9(2):109-28. https://doi.org/10.1386/jaac.9.2.109_1.

18. Wilson C, Dadswell A, Munn-Giddings C, Bungay $H$. The role of participatory arts in developing reciprocal relationships amongst older people: a conceptual review of the literature. J Aging Soc Change. 2019;9(4):1-16. https://doi.org/10.18848/2576-5310/CGP/v09i04/1-16.

19. Poscia A, Stojanovic J, la Milia DI, Duplaga M, Grysztar M, Moscato U, et al. Interventions targeting loneliness and social isolation among the older people: an update systematic review. Exp Gerontol. 2018;102:133-44. https://doi.org/10.1016/j.exger.2017.11.017.

20. Cohen-Mansfield J, Perach R. Interventions for alleviating loneliness among older persons: a critical review. Am J Health Promot. 2015;29(3):e109-25. https://doi.org/10.4278/ajhp.130418-LIT-182.

21. Overgaard I, Sørensen NØ. Can an art museum help in combating loneliness? J Appl Arts Health. 2015;6(2):187-203. https://doi.org/10.1386/jaa h.6.2.187_1.

22. Todd C, Camic PM, Lockyer B, Thomson LJM, Chatterjee HJ. Museumbased programs for socially isolated older adults: understanding what works. Health Place. 2017;48:47-55. https://doi.org/10.1016/j.healthplace.2 017.08.005.

23. Tymoszuk U, Perkins R, Fancourt D, Williamon A. Cross-sectional and longitudinal associations between receptive arts engagement and loneliness among older adults. Soc Psychiatry Psychiatr Epidemiol. 2019; 55(7):891-900. https://doi.org/10.1007/s00127-019-01764-0.

24. Bennington R, Backos A, Harrison J, Etherington Reader A, Carolan R. Art therapy in art museums: promoting social connectedness and psychological well-being of older adults. Arts Psychother. 2016;49:34-43. https://doi.org/1 0.1016/j.aip.2016.05.013.

25. Matthew D, Sundar S, Subramaniam E, Parmar P. Music therapy as group singing improves geriatric depression scale score and loneliness in institutionalized geriatric adults with mild depression: a randomized controlled study. Int J Educ Psychol Res. 2017;3:6-10.

26. Bensimon $M$, Amir $D$, Wolf $Y$. Drumming through trauma: music therapy with post-traumatic soldiers. Arts Psychother. 2008;35(1):34-48. https://doi org/10.1016/j.aip.2007.09.002.

27. Perkins R, Ascenso S, Atkins L, Fancourt D, Williamon A. Making music for mental health: how group drumming mediates recovery. Psychol WellBeing. 2016;6(1):11. https://doi.org/10.1186/s13612-016-0048-0.

28. Fancourt $D$, Perkins $R$. The effects of mother-infant singing on emotional closeness, affect, anxiety, and stress hormones. Music Sci. 2018;1: 205920431774574. https://doi.org/10.1177/2059204317745746.

29. Pearce E, Launay J, Dunbar RIM. The ice-breaker effect: singing mediates fast social bonding. R Soc Open Sci. 2015;2(10):150221. https://doi.org/10.1098/ rsos.150221.

30. Bullack A, Gass C, Nater UM, Kreutz G. Psychobiological effects of choral singing on affective state, social connectedness, and stress: influences of singing activity and time course. Front Behav Neurosci. 2018;12:223. https:// doi.org/10.3389/fnbeh.2018.00223.

31. Cohen GD, Perlstein S, Chapline J, Kelly J, Firth KM, Simmens S. The impact of professionally conducted cultural programs on the physical health, mental health, and social functioning of older adults. The Gerontologist. 2006;46(6):726-34. https://doi.org/10.1093/geront/46.6.726.
32. Schäfer K, Saarikallio S, Eerola T. Music may reduce loneliness and act as social surrogate for a friend: evidence from an experimental listening study. Music Sci. 2020;3:205920432093570. https://doi.org/10.1177/20592 04320935709

33. Schäfer K, Eerola T. How listening to music and engagement with other media provide a sense of belonging: an exploratory study of social surrogacy. Psychol Music. 2020;48(2):232-51. https://doi.org/10.1177/030573 5618795036.

34. Thoma MV, Ryf S, Mohiyeddini C, Ehlert U, Nater UM. Emotion regulation through listening to music in everyday situations. Cogn Emot. 2012;26(3): 550-60. https://doi.org/10.1080/02699931.2011.595390.

35. Hays T, Minichiello $V$. The meaning of music in the lives of older people: a qualitative study. Psychol Music. 2005;33(4):437-51. https://doi.org/10.1177/ 0305735605056160

36. Rane-Szostak D, Herth KA. Pleasure Reading, other activities, and loneliness in later life. J Adolscent Adult Lit. 1995;39:100-8.

37. Toepoel V. Ageing, leisure, and social connectedness: how could leisure help reduce social isolation of older people? Soc Indic Res. 2013;113(1):35572. https://doi.org/10.1007/s11205-012-0097-6.

38. Nadasen K. "Life without line dancing and the other activities would be too dreadful to imagine": an increase in social activity for older women. J Women Aging. 2008;20(3-4):329-42. https://doi.org/10.1080/08952840801 985060 .

39. Tarr B, Launay J, Dunbar RIM. Music and social bonding: "self-other" merging and neurohormonal mechanisms. Front Psychol. 2014;5. https:// doi.org/10.3389/fpsyg.2014.01096

40. Nevay S, Robertson L, Lim CSC, Moncur W. Crafting textile connections: a mixed-methods approach to explore traditional and e-textile crafting for wellbeing. Des J. 2019;22(sup1):487-501. https://doi.org/10.1080/14606925.2 019.1595434.

41. Pöllänen SH, Weissmann-Hanski MK. Hand-made well-being: textile crafts as a source of eudaimonic well-being. J Leis Res. 2020;51(3):348-65. https://doi. org/10.1080/00222216.2019.1688738.

42. Greaves CJ, Farbus L. Effects of creative and social activity on the health and well-being of socially isolated older people: outcomes from a multi-method observational study. J R Soc Promot Heal. 2006;126(3):134-42. https://doi. org/10.1177/1466424006064303.

43. Jang M, Kim Y. The effect of group sandplay therapy on the social anxiety, loneliness and self-expression of migrant women in international marriages in South Korea. Arts Psychother. 2012;39(1):38-41. https://doi.org/10.1016/j.a ip.2011.11.008.

44. Kelly D, Steiner A, Mazzei M, Baker R. Filling a void? The role of social enterprise in addressing social isolation and loneliness in rural communities. J Rural Stud. 2019;70:225-36. https://doi.org/10.1016/j. jrurstud.2019.01.024

45. Lowe SS. Creating Community: Art for community development. J Contemp Ethnogr. 2000;29(3):357-86. https://doi.org/10.1177/089124100129023945.

46. Kay A. Art and community development: the role the arts have in regenerating communities. Commun Dev J. 2000;35(4):414-24. https://doi. org/10.1093/cdj/35.4.414

47. Papinczak ZE, Dingle GA, Stoyanov SR, Hides L, Zelenko O. Young people's uses of music for well-being. J Youth Stud. 2015;18(9):1119-34. https://doi. org/10.1080/13676261.2015.1020935.

48. O'Neill, S. A. Entangled musical lives: Affordances of spaces in young people's music engagement for connectedness and wellbeing. in Handbook of Music, Adolescents, and Wellbeing (eds. McFerran, K., Derrington, P. \& Saarikallio, S.) 175-186 (Oxford University Press, 2019). doi: https://doi.org/10.1093/oso/9780198808992.003.0016.

49. North AC, Hargreaves DJ. Music and adolescent identity. Music Educ Res. 1999;1(1):75-92. https://doi.org/10.1080/1461380990010107.

50. Bennett, A. \& Nikulinsky, L. Wellbeing, young people, and music scenes. in Handbook of Music, Adolescents, and Wellbeing (eds. McFerran, K., Derrington, P. \& Saarikallio, S.) 187-196 (Oxford University Press, 2019). doi: https://doi.org/10.1093/oso/9780198808992.003.0017.

51. Daykin N, de Viggiani N, Moriarty Y, Pilkington P. Music-making for health and wellbeing in youth justice settings: mediated affordances and the impact of context and social relations. Sociol Health IIIn. 2017;39(6):941-58. https://doi.org/10.1111/1467-9566.12549.

52. Gardner SM, Komesaroff P, Fensham R. Dancing beyond exercise: young people's experiences in dance classes. J Youth Stud. 2008;11(6):701-9. https://doi.org/10.1080/13676260802393294. 
53. Muro A, Artero N. Dance practice and well-being correlates in young women. Women Health. 2017:57(10):1193-203. https://doi.org/10.1080/0363 0242.2016 .1243607$.

54. Koch SC, Mehl L, Sobanski E, Sieber M, Fuchs T. Fixing the mirrors: a feasibility study of the effects of dance movement therapy on young adults with autism spectrum disorder. Autism. 2015;19(3):338-50. https://doi.org/1 $0.1177 / 1362361314522353$

55. Bradley BS, Deighton J, Selby J. The 'voices' project: capacity-building in community development for youth at risk. J Health Psychol. 2004;9(2):197212. https://doi.org/10.1177/1359105304040887.

56. Tymoszuk U, Spiro N, Perkins R, Mason-Bertrand A, Gee K, Williamon A. Arts engagement trends in the United Kingdom and their mental and social wellbeing implications: HEartS survey. Plos One. 2021;16(3):e0246078. https://doi.org/10.1371/journal.pone.0246078.

57. Lee RM, Dean BL, Jung K-R. Social connectedness, extraversion, and subjective well-being: testing a mediation model. Personal Individ Differ. 2008;45(5):414-9. https://doi.org/10.1016/j.paid.2008.05.017.

58. Hughes ME, Waite LJ, Hawkley LC, Cacioppo JT. A short scale for measuring loneliness in large surveys: results from two population-based studies. Res Aging. 2004;26(6):655-72. https://doi.org/10.1177/0164027504268574.

59. Russell D, Peplau LA, Cutrona CE. The revised UCLA loneliness scale: concurrent and discriminant validity evidence. J Pers Soc Psychol. 1980; 39(3):472-80. https://doi.org/10.1037/0022-3514.39.3.472.

60. Karim J, Weisz R, Bibi Z, ur Rehman S. Validation of the Eight-Item Center for Epidemiologic Studies Depression Scale (CES-D) Among Older Adults. Curr Psychol. 2015;34:681-92

61. Williamon A, Tymoszuk U, Spiro N, Gee K, Mason-Bertrand A, Perkins R. HEartS survey 2019: charting the health, economic, and social impact of the arts, Dryad, dataset. 2021. https://doi.org/10.5061/dryad.3r2280gdj.

62. Wang J, Lloyd-Evans B, Giacco D, Forsyth R, Nebo C, Mann F, et al. Social isolation in mental health: a conceptual and methodological review. Soc Psychiatry Psychiatr Epidemiol. 2017;52(12):1451-61. https://doi.org/10.1007/ s00127-017-1446-1.

63. Anderson, S. \& Bigby, C. Community participation as identity and belonging: a case study of Arts Project Australia. "I am an artist". Res Pract Intellect Dev Disabil. 1-14 (2020) doi:https://doi.org/10.1080/23297018.2020.1753231.

64. Coan S, Woodward J. An evaluation of hive connecting creativity; 2017.

65. Hall E. Making and gifting belonging: creative arts and people with learning disabilities. Environ Plan Econ Space. 2013;45(2):244-62. https://doi.org/10.1 068/a44629.

66. Hiltunen, K. E. et al. Anchoring Belonging Through Material Practices in Participatory Arts-Based Research. Forum Qual. Sozialforschung Forum Qual. Soc. Res. Vol 21, No 2 (2020): Challenging Times-Qualitative Methods and Methodological Approaches to Research on Time (2020).

67. Meeks S, Shryock S, Vandenbroucke R. Theatre audience members' positive affect, belonging, social interaction, and flow related to 2-year well-being. Innov Aging. 2018;2(suppl_1):122-3. https://doi.org/10.1093/ geroni/igy023.450

68. Stickley T. The arts, identity and belonging: a longitudinal study. Arts Health. 2010;2(1):23-32. https://doi.org/10.1080/17533010903031614.

69. Jafari A, Taheri B, vom Lehn D. Cultural consumption, interactive sociality, and the museum. J Mark Manag. 2013;29:1729-52.

70. Derrick JL, Gabriel S, Hugenberg K. Social surrogacy: how favored television programs provide the experience of belonging. J Exp Soc Psychol. 2009; 45(2):352-62. https://doi.org/10.1016/j.jesp.2008.12.003.

71. Haslam, C., Jetten, J., Cruwys, T., Dingle, G. A. \& Haslam, S. A. The new psychology of health: unlocking the social cure. (Routledge, 2018).

72. Sani F, Herrera M, Wakefield JRH, Boroch O, Gulyas C. Comparing social contact and group identification as predictors of mental health: social contact and group identification as predictors of mental health. $\mathrm{Br} J \mathrm{Soc}$ Psychol. 2012;51(4):781-90. https://doi.org/10.1111/j.2044-8309.2012.02101.x.

73. Williams E, Dingle GA, Jetten J, Rowan C. Identification with arts-based groups improves mental wellbeing in adults with chronic mental health conditions. J Appl Soc Psychol. 2019;49(1):15-26. https://doi.org/10.1111/ja sp.12561.

74. Forbes, M. "We're pushing back": Group singing, social identity, and caring for a spouse with Parkinson's. Psychol. Music 030573562094423 (2020) doi: https://doi.org/10.1177/0305735620944230.

75. Maidment J, Macfarlane S. Craft groups: sites of friendship, empowerment, belonging and learning for older women. Groupwork. 2009;19(1):10-25. https://doi.org/10.1921/095182409X471802.
76. Siegrist J, von dem Knesebeck O, Pollack CE. Social productivity and wellbeing of older people: a sociological exploration. Soc Theory Health. 2004; 2(1):1-17. https://doi.org/10.1057/palgrave.sth.8700014.

77. Cameron F. Contentiousness and shifting knowledge paradigms: the roles of history and science museums in contemporary societies. Mus Manag Curatorship. 2005;20(3):213-33. https://doi.org/10.1080/09647770500502003.

78. Cameron F. Transcending fear - engaging emotions and opinion - a case for museums in the 21st century. Open Mus J. 2003;6:1-46.

79. Casey D. Museums as agents for social and political change. Australas Sci. 2002;23:18-9.

80. Bentwich ME, Gilbey P. More than visual literacy: art and the enhancement of tolerance for ambiguity and empathy. BMC Med Educ. 2017;17(1):200 https://doi.org/10.1186/s12909-017-1028-7.

81. Parkins JR, Mitchell RE. Public participation as public debate: a deliberative turn in natural resource management. Soc Nat Resour. 2005;18(6):529-40. https://doi.org/10.1080/08941920590947977.

82. Perkins R, Mason-Bertrand A, Fancourt D, Baxter L, Williamon A. How participatory music engagement supports mental well-being: a metaethnography. Qual Health Res. 2020;30(12):1-133. https://doi.org/10.1177/1 049732320944142.

83. Fancourt, D. \& Finn, S. What is the evidence on the role of the arts in improving health and well-being? A scoping review. Health Evid Netw Synth Rep. 67. (2019).

84. Brower RL, Jones TB, Osborne-Lampkin L, Hu S, Park-Gaghan TJ. Big Qual: defining and debating qualitative inquiry for large data sets. Int J Qual Methods. 2019;18:160940691988069. https://doi.org/10.1177/160940691 9880692.

\section{Publisher's Note}

Springer Nature remains neutral with regard to jurisdictional claims in published maps and institutional affiliations.
Ready to submit your research? Choose BMC and benefit from:

- fast, convenient online submission

- thorough peer review by experienced researchers in your field

- rapid publication on acceptance

- support for research data, including large and complex data types

- gold Open Access which fosters wider collaboration and increased citations

- maximum visibility for your research: over $100 \mathrm{M}$ website views per year

At BMC, research is always in progress.

Learn more biomedcentral.com/submissions 